OPEN ACCESS

Edited by:

Robert Kourist,

Graz University of Technology, Austria

Reviewed by:

Hugo Gramajo,

Consejo Nacional de Investigaciones

Científicas y Técnicas (CONICET),

Argentina

Loreto Parra,

Pontificia Universidad Católica de Chile, Chile

*Correspondence:

Felipe Lombó

lombofelipe@uniovi.es

Specialty section:

This article was submitted to Microbiotechnology, Ecotoxicology and Bioremediation,

a section of the journal Frontiers in Microbiology

Received: 01 October 2016 Accepted: 08 May 2017 Published: 30 May 2017

Citation: Marín L, Gutiérrez-del-Río I, Yagüe $P$, Manteca Á, Villar CJ and Lombó $F$ (2017) De Novo Biosynthesis of Apigenin, Luteolin, and Eriodictyol in the Actinomycete Streptomyces albus and Production Improvement by Feeding and Spore Conditioning.

Front. Microbiol. 8:921. doi: 10.3389/fmicb.2017.00921

\section{De Novo Biosynthesis of Apigenin, Luteolin, and Eriodictyol in the Actinomycete Streptomyces albus and Production Improvement by Feeding and Spore Conditioning}

\author{
Laura Marín, Ignacio Gutiérrez-del-Río, Paula Yagüe, Ángel Manteca, Claudio J. Villar \\ and Felipe Lombó*
}

Biotechnology in Nutraceuticals and Bioactive Compounds-BIONUC, Departamento de Biología Funcional, Área de Microbiología, University of Oviedo, Oviedo, Spain

Nutraceutical compounds as plant flavonoids play an important role in prevention and modulation of diverse heath conditions, as they exert interesting antifungal, antibacterial, antioxidant, and antitumor effects. They also possess anti-inflammatory activities in arthritis, cardiovascular disease or neurological diseases, as well as modulatory effects on the CYP450 activity on diverse drugs. Most flavonoids are bioactive molecules of plant origin, but their industrial production is sometimes hindered due to reasons as low concentration in the plant tissues, presence in only some species or as a complex mixture or inactive glycosides in plant vacuolae. In this work, we describe the de novo biosynthesis of two important flavones, apigenin and luteolin, and one known flavanone, eriodictyol. Their plant biosynthetic pathways have been reconstructed for heterologous expression in Streptomyces albus, an actinomycete bacterium manageable at industrial production level. Also, production levels for apigenin have been improved by feeding with naringenin precursor, and timing for settlement of secondary metabolism has been advanced by spore conditioning. In the cases of eriodictyol and luteolin, their production in this important type of biotechnology-prone bacteria, the actinomycetes, had not been described in the literature yet.

Keywords: flavonoid, flavone, flavanone, polyphenol, nutraceutical, antioxidant, anti-inflammatory

\section{INTRODUCTION}

Polyphenols are one of the largest and widely natural products distributed in plant cells, since more than 10,000 phenolic compounds have been described so far in higher plants, with several 100 found in edible plants (Manach et al., 2004; Tsao, 2010; Li et al., 2014). Flavonoids (Latin flavus, "yellow") represent $60 \%$ of these polyphenols and cover more than 6000 compounds ubiquitously distributed in plants (Chaudhuri et al., 2013; González-Vallinas et al., 2013).

All flavonoids have a generic chemical structure consisting of 15 carbon atoms (C6-C3-C6): two aromatic rings (rings $\mathrm{A}$ and $\mathrm{B}$ ) connected by a heterocyclic pyran $\mathrm{C}$ which contains one oxygen (ring C, Figure 1) (Kumar and Pandey, 2007; Verma and Pratap, 2010; Liu, 2013; Ravishankar et al., 2013; Fantini et al., 2015). This basic skeleton can have multiple substituents, as hydroxyl groups as 

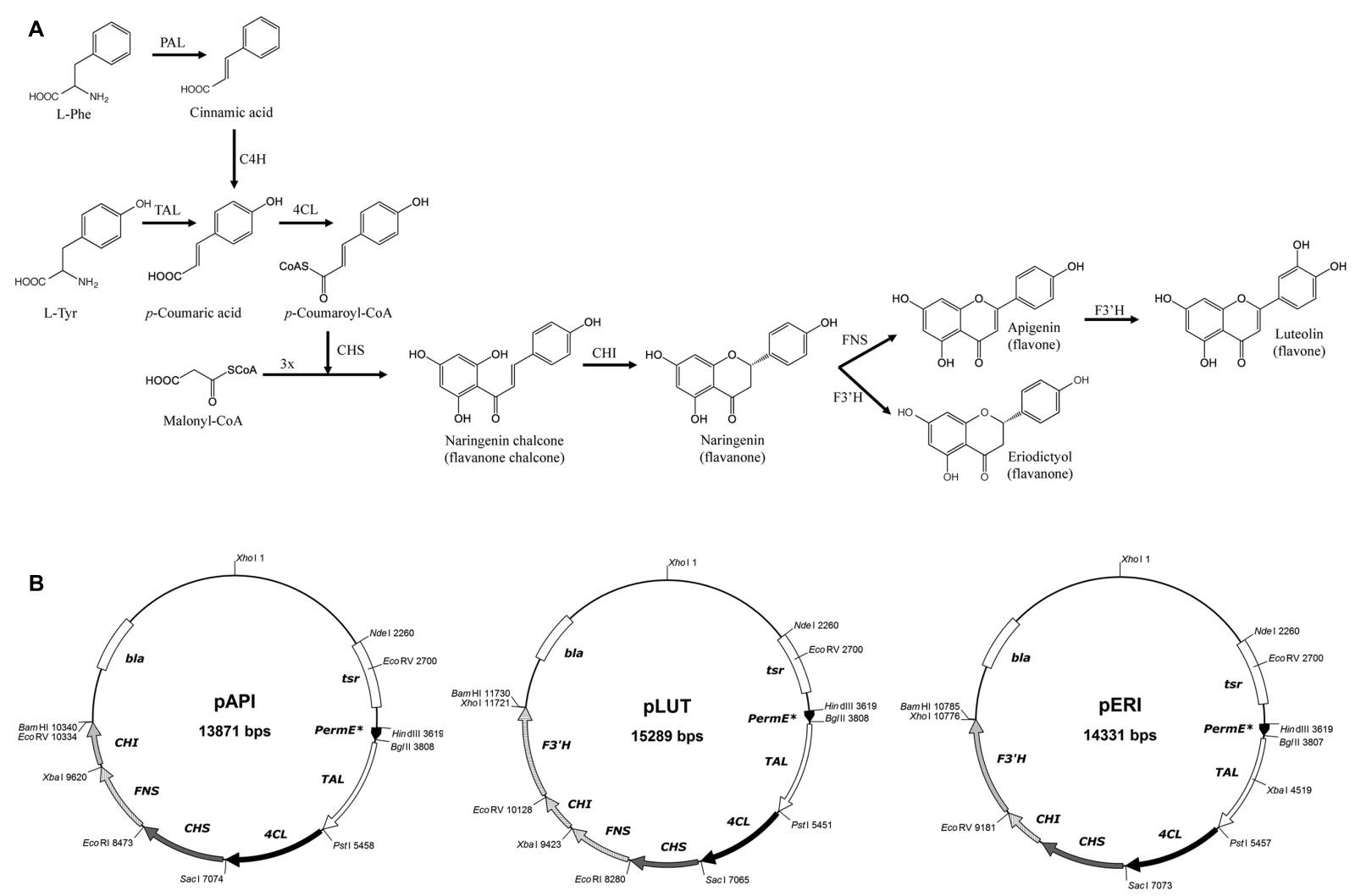

FIGURE 1 | (A) Biosynthetic pathway for biosynthesis of the flavones apigenin and luteolin and the flavanone eriodictyol in plants (Using PAL and C4H) and in Streptomyces albus (suing TAL). (B) Recombinant plasmids constructed in this work for the heterologous biosynthesis of these flavonoids.

well as sugars (Crozier et al., 2009). Depending on the pattern of hydroxylation and the substituents on the heterocyclic ring C, flavonoids can be classified into several sub-groups, but in this paper we focus on two groups: flavones as luteolin (present in Thai chili, broccoli and leaves of onion and celery) and apigenin (present in parsley, celery, onion, garlic, red pepper, and chamomile tea); and flavanones (as eriodictyol found in citrus fruits such as orange, lemon, or grapefruit) (Manach et al., 2004; Tsao, 2010; Liu, 2013).

The biological activities of these compounds depend both on their structural differences and glycosylation patterns (Kumar and Pandey, 2007; Tsao, 2010). In fact, diet flavonoids can promote health and prevent certain diseases such as cancer by acting against cell oxidation processes and by stopping cell degradation and aging (Luo et al., 2015).

The effects of flavonoids in humans can be attributed to antioxidant, antitumor, anti-inflammatory, antimicrobial, anticancer, and cardiovascular actions. For example, eriodictyol performs a key role against the pathogenesis of diabetes mellitus, inhibiting immunoglobulin E/antigen-produced type I hypersensitivity. This flavanone also shows antinociceptive, hyperthermic, and anticancer effects (Zhu L. et al., 2014). Apigenin has a growing importance due to its inhibitory effect on the PI3K/Akt/mTOR signaling pathways (Tong and
Pelling, 2013). Luteolin is able to inhibit angiogenesis or to reduce tumor size in vivo since it is able to modulate protein kinases and growth factor receptors as EGFRs or VEGFRs (López-Lázaro, 2006). Also, the antioxidant capacity of these and other polyphenols acts as master key in preventing numerous diseases associated with oxidative damage such as cardiovascular, neurodegenerative and cancer (Ravishankar et al., 2013; Hollman, 2014).

Flavonoids are synthesized in planta by the phenylpropanoid pathway, which converts L-Phe in 4-coumaroyl-CoA in three steps, the common intermediate for all flavonoids (Figure 1) (Falcone Ferreyra et al., 2012). These first three common steps are catalyzed by phenylalanine ammonia lyase $(\mathrm{PAL})$, cinnamate 4-hydroxylase $(4 \mathrm{CH})$ and 4-coumaroyl $\mathrm{CoA}$ ligase (4CL) (Figure 1). Then the chalcone synthase (CHS) condenses a molecule of 4-coumaroyl-CoA with three molecules of malonyl-CoA, generating naringenin chalcone, the basic skeleton for all flavonoids (Tsao, 2010; Wang et al., 2011; Falcone Ferreyra et al., 2012). The heterocycle C closure is catalyzed by chalcone isomerase (CHI), which generates naringenin, the precursor for apigenin and luteolin (flavones) and for eriodictyol (flavanone). In order to generate apigenin, the flavone synthase (FNS) oxidoreductase is required. Apigenin is then the substrate for the flavonoid $3^{\prime}$-hydroxylase $\left(\mathrm{F}^{\prime} \mathrm{H}\right)$, giving rise to luteolin (Figure 1). On the other 
hand, naringenin is also the substrate for $\mathrm{F}^{\prime} \mathrm{H}$, generating eriodictyol without FNS activity (Figure 1) (Crozier et al., 2009).

Flavonoids are valuable compounds for use in the pharmaceutical, chemical and nutraceutical industry, but the amounts that can be obtained directly from plants are very limited. One solution is the chemical synthesis, but when dealing with metabolites with complex chemical structures, their production is economically not feasible in most cases. Therefore, an attractive alternative is to express these plant biosynthetic gene pathways in microbial factories, using combinatorial biosynthesis, where genes from different organisms are grouped in an artificial gene cluster directed to the production of the natural bioactive compound (Falcone Ferreyra et al., 2012; Trantas et al., 2015). Microorganisms that are most commonly used as cell factories for flavonoids are Saccharomyces cerevisiae, Escherichia coli and in some cases Streptomyces venezuelae, where different techniques are applied in order to increase production levels.

However, in the last years, focus has been made in de novo processes for flavonoids microbial production, without adding expensive precursors to the culture medium, therefore allowing cheap production platforms necessary for broad commercial use of flavonoids as nutraceuticals (Fowler and Koffas, 2009; Wang et al., 2011; Wu et al., 2014). In this work, we have achieved de novo production of apigenin, luteolin, and eriodictyol by means of synthetic biosynthetic pathways heterologous expressed in Streptomyces albus. The use of Gram-positive bacterial factories, as this actinomycete, facilitates the further industrialization of bioactive compounds for the pharmaceutical industry, as on the one hand, actinomycetes are the most diverse and rich producers of bioactive compounds (antibacterials, antifungals, antitumors, herbicides, immunosuppressors, etc.), belonging to many different biochemical families (lactams, polyketides, non-ribosomal peptides, terpenoids, flavonoids, etc.), and providing all the necessary metabolic precursors and biosynthetic machinery for these purposes, including also all post-translationally modification enzymes (Newman and Cragg, 2007). Actually, about two thirds of all known bioactive polyketides are produced by actinomycetes. This huge biosynthetic capability is accompanied also by a huge diversity in resistance mechanisms to allow production of such a wide range of bioactive compounds (Zhang et al., 2008; Hwang et al., 2014). This role as useful bacterial factories for bioactives is reinforced in the case of some actinomycetes as Saccharopolyspora erythraea, S. coelicolor, S. lividans, S. avermitilis, S. venezuelae and $S$. albus, as their genomes have been sequenced and multiple genetic manipulation tools are available for them. Specifically, in the case of $S$. albus, this host is more convenient as it shows a fast and nice disperse mycelial growth, instead of the most common mycelial dense aggregates shown in the case of other actinomycetes. This disperse growth facilitates scaling-up at industrial bioreactors, as less complications arise from local cellular density and cell lysis. Also, S. albus can be transformed with methylated plasmid DNA, in contrast to other actinomycetes, which also facilitates genetic engineering in this species (Kieser et al., 2000).

\section{MATERIALS AND METHODS}

\section{Bacterial Strains, Plasmids, and Culture Conditions}

Escherichia coli TOP10 (Invitrogen) and pUC57 (Fermentas) were used for routine sub-cloning. The high-copy number shuttle vector pIAGO (Table 1) for E. coli-Streptomyces, which contains the strong constitutive ermE promoter $\mathrm{P}_{\text {ermE* }}$ (Aguirrezabalaga et al., 2000), was used as expression plasmid in the strain S. albus J1074 (Chater and Wilde, 1980), which was used as host for the production of flavones and flavanones (Table 2).

Escherichia coli was grown at $37^{\circ} \mathrm{C}$ in TSB liquid broth or TSB agar (VWR), supplemented with the corresponding antibiotics for plasmid selection (ampicillin $100 \mu \mathrm{g} / \mathrm{ml}$, Sigma Aldrich). S. albus $\mathrm{J} 1074$ was grown at $30^{\circ} \mathrm{C}$ in YEME $17 \%$ sucrose (Kieser et al., 2000) for the preparation of protoplasts. It was sporulated on Bennet medium (Kieser et al., 2000), and supplemented with the corresponding antibiotics when necessary (thiostrepton $50 \mu \mathrm{g} / \mathrm{ml}$, Sigma Aldrich).

For flavonoids production, S. albus clones were grown in $25 \mathrm{ml}$ of R5A medium (Fernández et al., 1998), supplemented with the corresponding antibiotic, during $184 \mathrm{~h}$ (96 h for feeding

TABLE 1 | List of plasmids used in this study.

\begin{tabular}{|c|c|c|}
\hline Plasmid & Description & Source \\
\hline pIAGO & $\begin{array}{l}\text { pWHM3 (replicative shuttle vector) } \\
\text { harboring permE* }\end{array}$ & $\begin{array}{l}\text { Aguirrezabalaga } \\
\text { et al., } 2000\end{array}$ \\
\hline pSL1180 & E. coli vector & Brosius, 1989 \\
\hline pUC57 & E. coli vector & Fermentas \\
\hline pLMF1 & pUC57 harboring TAL & This study \\
\hline pLMF2 & pUC57 harboring $4 \mathrm{CL}$ & This study \\
\hline pLMF3 & pUC57 harboring CHS & This study \\
\hline pLMF5 & pUC57 harboring $\mathrm{CHI}$ & This study \\
\hline pLMF-FNS & pUC57 harboring FNS & This study \\
\hline pLMF7 & pSL1180 harboring TAL & This study \\
\hline pLMF8 & pSL1180 harboring TAL and 4CL & This study \\
\hline pNGM1 & pSL1180 harboring CHS and FNS & This study \\
\hline pNGM2 & $\begin{array}{l}\text { pSL1180 harboring TAL, 4CL, CHS, and } \\
\text { FNS }\end{array}$ & This study \\
\hline pNGM3 & $\begin{array}{l}\text { pSL1180 harboring TAL, 4CL, CHS, FNS, } \\
\text { and CHI }\end{array}$ & This study \\
\hline pAPI & $\begin{array}{l}\text { plAGO harboring TAL, 4CL, CHS, FNS, and } \\
\mathrm{CHI}\end{array}$ & This study \\
\hline pNGM4 & $\begin{array}{l}\text { pSL1180 harboring TAL, 4CL, CHS, F3'H, } \\
\text { and } \mathrm{CHI}\end{array}$ & This study \\
\hline pERI & $\begin{array}{l}\text { plAGO harboring TAL, } 4 \mathrm{CL}, \mathrm{CHS}, \mathrm{F}^{\prime} \mathrm{H} \text {, } \\
\text { and } \mathrm{CHI}\end{array}$ & This study \\
\hline pNGM5 & $\begin{array}{l}\text { pSL1180 harboring TAL, 4CL, CHS, FNS, } \\
\mathrm{CHI} \text {, and FЗ' } \mathrm{F} \text {. }\end{array}$ & This study \\
\hline pLUT & $\begin{array}{l}\text { plAGO harboring TAL, } 4 \mathrm{CL}, \mathrm{CHS} \text {, FNS, } \\
\mathrm{CHI} \text {, and F3'H }\end{array}$ & This study \\
\hline
\end{tabular}


TABLE 2 | List of strains used in this study.

\begin{tabular}{lll}
\hline Strains & Description & Source \\
\hline E. coli TOP10 & $\begin{array}{l}\text { Strain used for routine sub-cloning } \\
\text { and transformation in S. albus }\end{array}$ & Invitrogen \\
Streptomyces albus & $\begin{array}{l}\text { Strain used to create the } \\
\text { flavonoid-producing mutants }\end{array}$ & Chater and \\
J1074 & $\begin{array}{l}\text { S. albus harboring pIAGO used as } \\
\text { negative control }\end{array}$ & This study \\
S. albus-pIAGO & S. albus harboring pAPI & This study \\
S. albus-pAPI & S. albus harboring pERI & This study \\
S. albus-pERI & S. albus harboring pLUT & This study \\
S. albus-pLUT & &
\end{tabular}

experiments) at $30^{\circ} \mathrm{C}$ and at $250 \mathrm{rpm}$. Spores were previously quantified and an inoculum of $10^{7} \mathrm{spores} / \mathrm{ml}$ was used always as inoculum.

\section{DNA Manipulation}

Restriction enzymes were purchased from Takara Biochemicals, T4 DNA ligase, Klenow fragment and Dream Taq DNA Polymerase from Thermo Scientific. Synthetic genes for the following ORFs (EBI preliminary accession number Hx2000056376) were generated by Genecust after codon optimization: TAL (as BglII-PstI gene cassette) from Rhodobacter capsulatus (GenBank accession no. WP_013066811), 4CL (as PstI-SacI gene cassette) from S. coelicolor (GenBank accession no. NP_628552), CHS (as SacI-EcoRI gene cassette) from Glycine $\max$ (GenBank accession no. L07647.1), CHI (as XbaI-EcoRV gene cassette) from G. max (GenBank accession no. AY595413.1), FNS (as EcoRI-XbaI gene cassette) from Petroselinum crispum (GenBank accession no. AY230247.1) and F3'H (as EcoRVBamHI gene cassette) from Arabidopsis thaliana (GenBank accession no. Q9SD85). Compatible restriction sites were added at each gene cassette end, in order to facilitate construction of the recombinant flavonoids gene clusters, as well as ribosome binding sites at the $5^{\prime}$-ends.

All constructed plasmids (Figure 1) described below were verified by restriction enzymes digestions and also by sequencing of the cloned regions. S. albus producing clones were confirmed by PCR by the use of oligonucleotides designed to amplify the junction site at the first two common genes (TAL and 4CL): $5^{\prime}$-GTGATCGAGCTGGACATGAA-3' as the forward primer and $5^{\prime}$-GGCGTCCACGAGGTGC-3' as the reverse primer.

\section{Construction of pAPI}

The plasmid pAPI is a pIAGO derivative (Table 1) containing the $\mathrm{P}_{\text {ermE* }}$ and the five genes responsible for apigenin de novo biosynthesis. All synthetic gene cassettes were independently cloned in pUC57 and those plasmids were named pLMF1 (pUC57 containing TAL gene), pLMF2 (4CL), pLMF3 (CHS), pLMF5 (CHI), and pLMF-FNS (FNS). Additionally, TAL gene was subcloned into vector pSL1180 as HindIII-BamHI (pLMF7) to start with the cloning strategy. 4CL gene (from pLMF2) was cloned into pLMF7 as PstI-BamHI gene cassette, generating
pLMF8. Next step was subcloning FNS gene cassette from pLMFFNS into pLMF3 as an EcoRI-XbaI DNA fragment, giving rise to pNGM1. The two gene cassettes from pNGM1 (CHS and FNS) were subcloned together into pLMF8 as SacI-BamHI DNA band, in order to get the first four genes together in a plasmid (pNGM2). Finally, CHI gene was subcloned into pNGM2 as $\mathrm{XbaI-BamHI}$ DNA fragment resulting in the generation of pNGM3, which contains the five genes required for apigenin biosynthesis.

As the expression host was Streptomyces, a further subcloning was required, and the $B g l \mathrm{II}-\mathrm{Bam} \mathrm{HI}$ DNA fragment from pNGM3 carrying these five genes was finally subcloned into a derivative of the bifunctional replicative vector pIAGO, under the control of $\mathrm{P}_{\text {ermE*}}$, giving rise to the final plasmid $\mathrm{pAPI}$.

\section{Construction of pLUT}

The plasmid pLUT (Table 1) directs the biosynthesis of luteolin and contains the six required genes (TAL, 4CL, CHS, CHI, FNS, and $\mathrm{F}^{\prime} \mathrm{H}$ ), as well as the $\mathrm{P}_{\text {ermE*}}$. This plasmid requires only one more gene $\left(\mathrm{F}^{\prime} \mathrm{H}\right)$ than those ones present in pAPI. Therefore, pNGM3 was used for the construction of pLUT. The gene cassette $\mathrm{F3}^{\prime} \mathrm{H}$ was subcloned into pNGM3 as an EcoRVBamHI DNA fragment. This plasmid was named pNGM5 and contains all six genes. These genes were further subcloned as a BglII-BamHI DNA fragment into the pIAGO vector, in order to achieve expression in S. albus, giving rise to plasmid pLUT.

\section{Construction of pERI}

The plasmid pERI (Table 1) contains the $\mathrm{P}_{\text {ermE* }}$ and the five genes required for the biosynthesis of eriodictyol. These genes are the ones encoding for TAL, 4CL, CHS, CHI, and $\mathrm{F}^{\prime}{ }^{\prime} \mathrm{H}$. As all the genes but the one coding for FNS are the same ones required to produce luteolin, the construction of the plasmid directing the biosynthesis of eriodictyol was based on the previously described plasmid, pNGM5. This plasmid was digested with EcoRI-XbaI, and then blunt-ended with Klenow fragment, to eliminate the gene cassette FNS. This new pSL1180 derivative plasmid was named pNGM4. In order to express these five genes in $S$. albus, they were subcloned in the replicative vector pIAGO as a BglII-BamHI DNA fragment, giving rise to the final plasmid, pERI.

\section{Extraction and Analysis of Flavonoids}

Spores from the different S. albus J1074 recombinant clones harboring pAPI, pERI, pLUT, and pIAGO (negative control) were incubated during $184 \mathrm{~h}$ in $25 \mathrm{ml}$ of liquid production medium R5A. Flavonoids extraction was carried out using three volumes of ethyl acetate and extracting separately the supernatant and the disrupted mycelium pellet (after acetone treatment). These extraction mixtures were incubated for $1 \mathrm{~h}$ in orbital shaker at room temperature. After this incubation, the organic phases were filtered, mixed together and concentrated by rotary evaporation and kept at $-20^{\circ} \mathrm{C}$ for later use. All cultivation experiments were carried out three times for each strain or analysis.

Dry extracts were dissolved in $200 \mu \mathrm{l}$ of methanol:DMSO (1:1), filtrated $(0.4 \mu \mathrm{m}$ cellulose filters) and analyzed by liquid chromatography-electrospray ionization mass spectrometry (HPLC-ESI-MS/MS, Agilent technologies 1290 Infinity, Triple 
Quadrupole). This chromatography was carried out using a Zorbax Eclipse Plus C18 column $(50 \mathrm{~mm} \times 2.1 \mathrm{~mm}, 1.8 \mu \mathrm{m})$ in the positive ion mode. The analytes were eluted at a flow rate of $0.3 \mathrm{~mL} / \mathrm{min}$ using a gradient of $0.1 \%(\mathrm{v} / \mathrm{v})$ formic acid in water $(\mathrm{A})$ and $0.1 \%(\mathrm{v} / \mathrm{v})$ formic acid in acetonitrile (B) at $0-10 \%$ of $\mathrm{B}$ for $1 \mathrm{~min}$, which was increased to $35 \%$ for $3 \mathrm{~min}$ and maintained at $35 \%$ for $1 \mathrm{~min}$; then increased to $80 \%$ for $3 \mathrm{~min}$ and maintained at $80 \%$ for 2 min and finally decreased to $10 \%$ for $1 \mathrm{~min}$.

Flavonoids quantification was carried out in multiple reaction monitoring (MRM) mode in MS/MS. To accomplish this, the following ion sets were selected to detect the transitions of the parent ions to the product ions specific to the analytes: naringenin $272>119 \mathrm{Da}$ and $272>151 \mathrm{Da}$; apigenin $270>117 \mathrm{Da}$ and $270>150 \mathrm{Da}$; eriodictyol $288>135 \mathrm{Da}$ and $288>150 \mathrm{Da}$; luteolin $286>131 \mathrm{Da}$ and $286>151 \mathrm{Da}$. Pure flavonoid standards were purchased from Sigma Aldrich (apigenin, eriodictyol, naringenin) and VWR (luteolin).

\section{Spore Conditioning Experiments}

Spore conditioning was carried out by incubating during 10 days a suspension of $10^{8}$ or $10^{9}$ spores $/ \mathrm{mL}$ in $5 \mathrm{~mL}$ R5A medium, at $30^{\circ} \mathrm{C}$ and $250 \mathrm{rpm}$, in $50 \mathrm{~mL}$ Falcon tubes (final spore concentrations of $10^{5}$ and $10^{6}$ spore equivalent $/ \mathrm{mL}$ respectively). This incubation was carried out in order to force spore germination in a high density culture, which induces programed cell death in mycelium I (MI), releasing the developmental signals that induce the differentiation (conditioning) of the MI cellular segments that remained viable into a new mycelium (MII), that is the secondary metabolite producer (Manteca et al., 2008). Due to the high density, this conditioned mycelium (MII), cannot growth too much, and remains quiescent until it is inoculated into a fresh medium (Manteca et al., 2008).

Thirty $\mu \mathrm{L}$ of the conditioned cultures (equivalent to $3 \times 10^{6}$ or $3 \times 10^{7}$ spores) were inoculated in $25 \mathrm{~mL} \mathrm{R} 5 \mathrm{~A}$ medium in a $250 \mathrm{~mL}$ buffled flask (triplicates). As a control, simultaneously, other flask triplicates with $25 \mathrm{~mL}$ R5A medium were inoculated with our standard conditions, $30 \mu \mathrm{L}$ of a spore stock solution (at $10^{10}$ spores $/ \mathrm{mL}$ ), which represents a final spore concentration in the flasks of $10^{7}$ spores $/ \mathrm{mL}$ All these nine flasks were incubated at $30^{\circ} \mathrm{C}$ and $250 \mathrm{rpm}$ during $168 \mathrm{~h}$, and samples were taken every $24 \mathrm{~h}$ : $20 \mu \mathrm{L}$ samples for confocal microscopy; $180 \mu \mathrm{L}$ samples for protein quantification using the Bradford method (Bradford, 1976) after boiling in $0.5 \mathrm{M} \mathrm{NaOH}$ for $10 \mathrm{~min}$ and after removing cellular debris by centrifugation (at $7740 \times g$ for $15 \mathrm{~min}$ ); and $1.5 \mathrm{~mL}$ for apigenin extraction and HPLC-MS quantification.

\section{Feeding Experiments}

Two hundred and fifty ml Erlenmeyer flasks with $25 \mathrm{~mL}$ R5A medium were inoculated with $10^{7}$ spores/mL of S. albus-pAPI and incubated at $30^{\circ} \mathrm{C}$ and $250 \mathrm{rpm}$ during $48 \mathrm{~h}$, according with previous literature (Park et al., 2009). At this time point, amounts of different precursors were added to achieve final concentrations of $1.2 \mathrm{mM}$ p-coumaric acid, $13.5 \mathrm{mM}$ sodium malonate, $1.2 \mathrm{mM}$ p-coumaric acid plus $13.5 \mathrm{mM}$ sodium malonate, or $0.1 \mathrm{mM}$ naringenin in the corresponding flasks (triplicates). $1.5 \mathrm{~mL}$ of each culture was extracted at $96 \mathrm{~h}$, as described in Section "Extraction and Analysis of Flavonoids," and apigenin was quantified by HPLC-MS. These final precursors concentrations were selected based in literature (Park et al., 2009, 2010).

\section{Laser Scanning Fluorescence Microscopy}

Streptomyces albus cultures from $24 \mathrm{~h}$ until $96 \mathrm{~h}$ were stained using the LIVE/DEAD BacLight Bacterial Viability Kit (Invitrogen), and observed under a Leica TCS-SP2-AOBS laser scanning microscope at wavelengths of 488 and $568 \mathrm{~nm}$ for excitation and 530 and $630 \mathrm{~nm}$ emission (optical sections of about $0.2 \mu \mathrm{m}$ ). Images were mixed with the Leica Confocal Software. In these conditions, living mycelium appears green colored (SYTO9 staining), while dying mycelium appears red (PI staining). Septa are visible as discontinuities in the SYTO9/PI stained hyphae; MI is fully compartmentalized, while MII (the secondary metabolite producer mycelium) is multinucleated with sporadic septa (Manteca et al., 2008).

\section{RESULTS}

\section{Heterologous Production of Apigenin}

The flavone apigenin is generated due to the action of the enzyme FNS (flavone synthase) on the important flavonoid precursor naringenina (Figure 1). In order to produce the plant metabolite naringenin in microorganisms, four enzymes are required: TAL, 4CL, CHS, and CHI (Figure 1). Four synthetic genes coding for these enzymes (adapted to the transcription and translation characteristics in prokaryotes as $S$. albus), together with a synthetic gene coding for FNS, were cloned in a replicative high-copy number shuttle vector for E. coli-Streptomyces, under the control of $\mathrm{P}_{\text {ermE* (see Materials and Methods). The final }}$ plasmid construction, pAPI, was transformed and successfully expressed in the actinomycete $S$. albus, as a method to achieve future industrial production of this important flavonoid.

Cultures of $S$. albus-pAPI in R5A liquid medium were analyzed by HPLC-MS chromatography in MRM in MS/MS mode, in order to identify and quantify the final product, apigenin, as well as its intermediate precursors naringenin and $p$-coumaric acid (Figure 1). $p$-Coumaric acid is the second common metabolite in flavonoids biosynthesis, after transformation of the initial aromatic amino acid precursor in plants (L-Phe) or in microorganisms (L-Tyr) (Figure 1). The three compounds ( $p$-coumaric acid, naringenin, and apigenin) were detected in these analyses and their yields were quantified using commercial pure standards (see Materials and Methods). Production rates for apigenin synthetized by $S$. albus-pAPI were $0.08 \mathrm{mg} / \mathrm{L}$. Its precursor naringenin was produced at lower level $(0.014 \mathrm{mg} / \mathrm{L})$, and the $p$-coumaric acid initial precursor for this pathway was observed at higher concentration, reaching levels of $0.774 \mathrm{mg} / \mathrm{L}$ (Figure 2). Negative control strain harboring the empty vector, S. albus-pIAGO showed no flavonoids in their HPLC-MS analyses. 


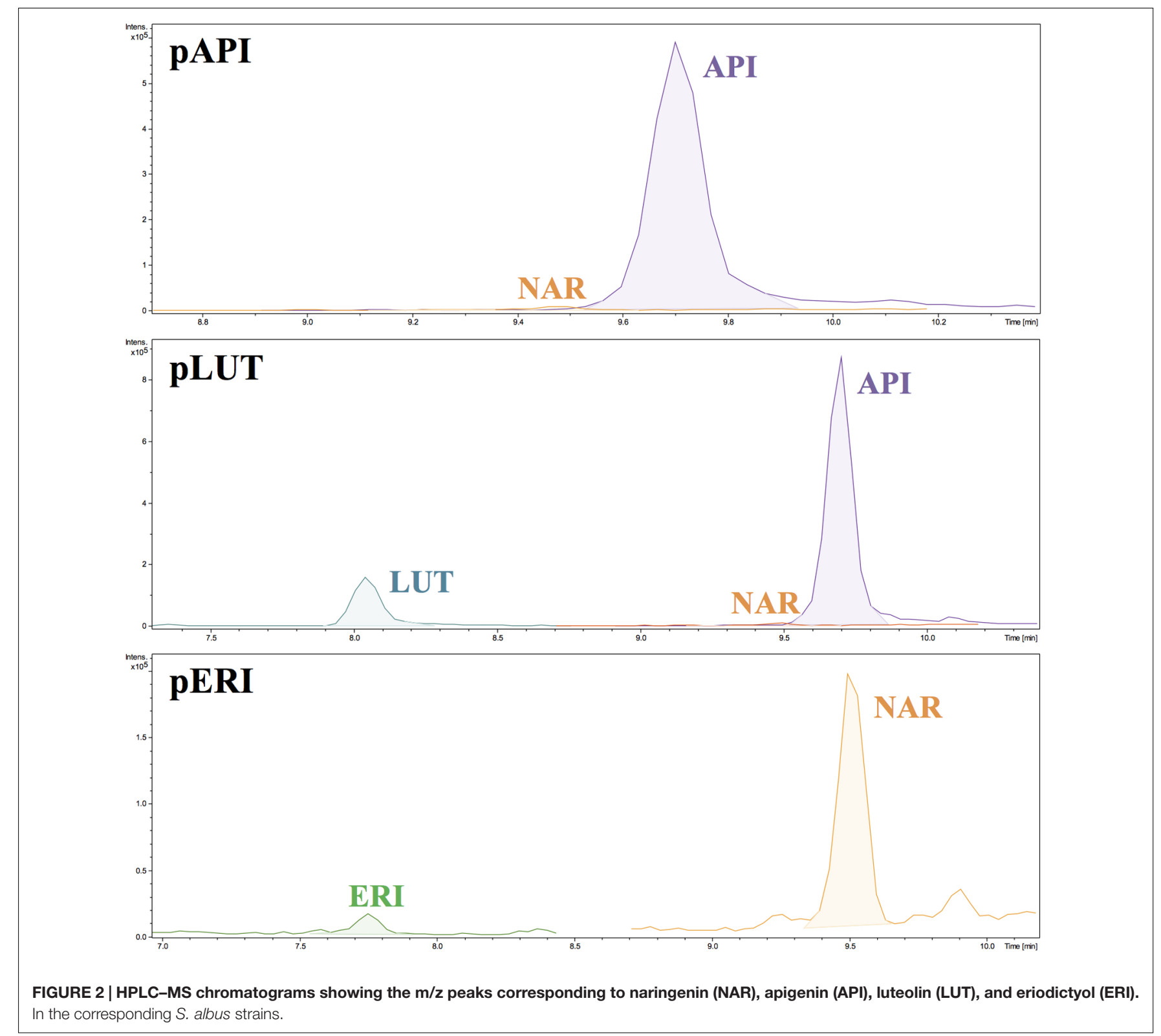

Differentiation of a multinucleated mycelium (MII) conditions secondary metabolism production (Manteca et al., 2008). Consequently, we tested the possibility to further improve apigenin production levels, or even anticipate time of maximum production, as a way to save money in future industrial fermentations, based in the improvement of the MII differentiation. Spore conditioning experiments were carried out with $S$. albus-pAPI (see Materials and Methods). Briefly, germination in dense spore inocula force programed cell death in the vegetative MI, releasing the developmental signals that induce the differentiation (conditioning) of the MI cellular segments that remained viable into a new mycelium (MII, secondary metabolite producer). Due to the high density, this conditioned mycelium (MII) remains quiescent until it is inoculated into a fresh medium (Manteca et al., 2008).
Conditioning times longer that these 10 days did not show extra advantages with respect to final effect in generation of quiescent MII. Also, after these 10 days, the obtained mycelium II remains quiescent and conditioned during a long time (at least months), ready to be used in different production batches (Manteca et al., 2008). Development and apigenin production were compared in cultures inoculated with conditioned and noncondtioned spores (Figures 3, 4). These experiments showed that inocula from conditioned cultures contained high amounts of dead mycelium pellets (red staining), non-germinated spores, and quiescent MII (green staining) (Figure 3B). By contrast, control cultures (non-conditioned inocula) contained only spores (Figure 3A). After $24 \mathrm{~h}$ incubation, control flasks showed normal development toward MI (Figure 3A), whereas conditioned flasks at this point showed a high proportion of 

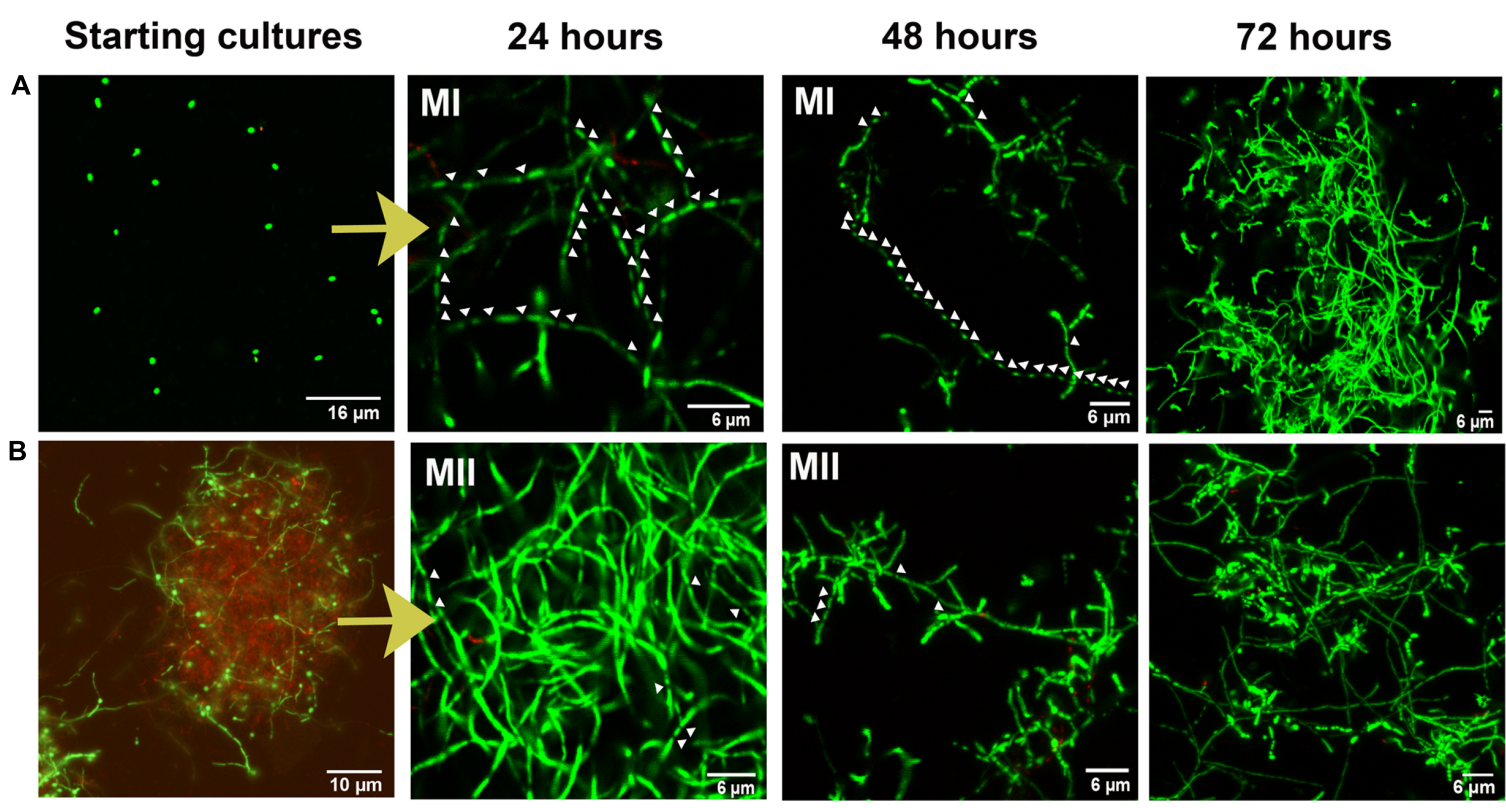

FIGURE 3 | Confocal laser-scanning fluorescence microscopy analysis (SYTO9/PI staining) of Streptomyces albus-pAPI development in liquid cultures under two different conditions. (A) morphology of control cultures inoculated with a spore preinoculum. (B) Morphology of conditioned cultures inoculated with a high-density pre-grown culture in which programed cell death processes was induced. Arrows indicate mycelium septa. MI: type I mycelium (compartmentalized mycelium); MII: type II mycelium (multinucleated mycelium, secondary metabolite producer).

producing MII (Figure 3B). Control flasks did not show a high proportion of MII until $72 \mathrm{~h}$ (Figure 3A). Accordingly, apigenin production was faster and the maximum production levels earlier in conditioned flasks $\left(72 \mathrm{~h}\right.$ for $10^{6}$ conditioned spore equivalent/mL flasks and $96 \mathrm{~h}$ for $10^{5}$ conditioned spore equivalent/mL flasks) than in the control flasks $\left(120 \mathrm{~h}, 10^{7}\right.$ spores/mL) (Figure 4).

Finally, in order to try to increase apigenin final production titers, feeding experiments were carried out (Figure 5). Feeding with coumaric acid, sodium malonate or both together did not increased significantly final apigenin titers $(0.139,0.106$, and $0.159 \mathrm{mg} / \mathrm{L}$ apigenin; in contrast to $0.082 \mathrm{mg} / \mathrm{L}$ in control without feeding). However, feeding with $0.1 \mathrm{mM}$ naringenin caused a statistically significant increase in apigenin production levels, achieving $0.384 \mathrm{mg} / \mathrm{L}$.

\section{Heterologous Production of Eriodictyol}

The flavanone eriodictyol is a hydroxylated form of the flavanone precursor naringenin. For its biosynthesis, only one extra enzymatic activity is required, the $\mathrm{F}^{\prime} \mathrm{H}$ (flavonoid $3^{\prime}$-hydroxylase) at ring $\mathrm{B}$ (Figure 1), instead of the FNS oxidoreductase. Final replacement in pAPI plasmid of the gene cassette coding for FNS by the new one coding for $\mathrm{F}^{\prime}{ }^{\prime} \mathrm{H}$ generated a vector containing the five genes (TAL, 4CL, CHS, CHI, and $\mathrm{F}^{\prime} \mathrm{H}$ ) required for eriodictyol biosynthesis in $S$. albus under the control of $\mathrm{P}_{\text {ermE* }}$ (see Materials and Methods).

This new recombinant plasmid, pERI, was transformed in S. albus protoplasts, and cultures from positive recombinant strains (in R5A liquid medium) were analyzed by MRM chromatography. These experiments demonstrated that recombinant plasmid pERI was able to redirect the biosynthesis from apigenin to eriodictyol in $S$. albus, using as common precursor the naringenin already detected in previous experiments. However, production levels for eriodictyol in these extracts were very low under these conditions $(0.002 \mathrm{mg} / \mathrm{L})$. However, higher levels of the naringenin precursor $(0.037 \mathrm{mg} / \mathrm{L})$ were observed. The initial precursor $p$-coumaric acid was also analyzed, showing production levels of $1.256 \mathrm{mg} / \mathrm{L}$ (Figure 2).

\section{Heterologous Production of Luteolin}

Luteolin biosynthesis in microorganisms requires the activity of six enzymes: TAL, 4CL, CHS, CHI, FNS, and F3' $\mathrm{H}$. The genes coding for these enzymes were cloned in the same replicative high-copy number shuttle vector for E. coli-Streptomyces (see Materials and Methods), under the control of the promoter $\mathrm{P}_{\text {ermE*, generating the final plasmid pLUT. This plasmid was }}$ transformed into $S$. albus protoplasts.

Clones of this recombinant strain were cultivated in $\mathrm{R} 5 \mathrm{~A}$ liquid medium and flavonoids productivity was quantified using HPLC-MS in their extracts. Luteolin was detected with production rates of $0.09 \mathrm{mg} / \mathrm{L}$ ) but its precursor apigenin was observed at higher levels $(0.085 \mathrm{mg} / \mathrm{L})$ (Figure 2$)$. As in previous experiments, a higher accumulation of the initial precursor p-coumaric acid was detected $(0.872 \mathrm{mg} / \mathrm{L})$.

\section{DISCUSSION}

In this work, S. albus has been able to de novo biosynthetize four flavonoids: naringenin (a flavanone precursor in this family of 

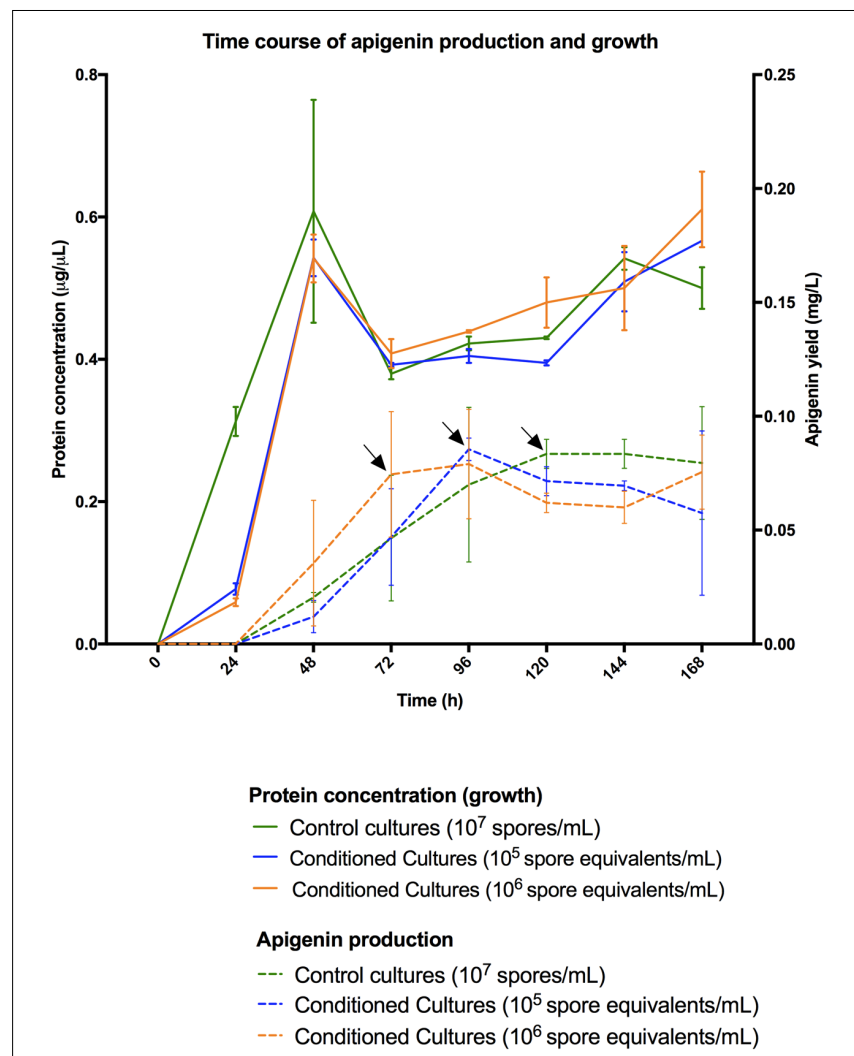

FIGURE 4 | Streptomyces albus-pAPI growth curves (solid lines) and apigenin production curves (dashed lines) for three different types of cultivation experiments (mean values from three independent triplicate flasks). Green colors correspond to control cultures with $10^{7}$ spores $/ \mathrm{mL}$. Blue colors correspond to conditioned cultures with a preinoculum of $10^{5}$ spore equivalents $/ \mathrm{mL}$. Orange colors correspond to conditioned cultures with a preinoculum of $10^{6}$ spore equivalents $/ \mathrm{mL}$. Apigenin production is anticipated in conditioned cultures, even with a delayed growth during the first 24-h, and achieving same production levels 1 and 2 days in advance, respectively. Maximum production levels for apigenin titers are labeled by arrows.

nutraceuticals), apigenin (its oxidized flavone derivative), luteolin (a 3'-hydroxylated apigenin) and eriodictyol (a 3'-hydroxylated version of the flavanone naringenin).

De novo naringenin production has been previously described in recombinant strains of E. coli (Hwang et al., 2003; Miyahisa et al., 2006; Santos et al., 2011), S. cerevisiae (Yan et al., 2005; Trantas et al., 2009), and S. clavuligerus (Álvarez-Álvarez et al., 2015). Other authors also achieved its production in other microorganisms, but after feeding with precursors (Park et al., 2009).

Apigenin was previously produced de novo only in E. coli (Miyahisa et al., 2006). Here, the complete biosynthetic pathway was cloned in E. coli and production levels reached up to $13 \mathrm{mg} / \mathrm{L}$. However, the addition to culture medium of the main precursor L-tyrosine at $543 \mathrm{mg} / \mathrm{L}(3 \mathrm{mM})$ was required (Miyahisa et al., 2006) (Table 3). In a more recent work, apigenin yields were increased to $23 \mathrm{mg} / \mathrm{L}$ in E. coli. But, as in the work developed by Miyahisa et al. (2006), its synthesis needed the supplementation

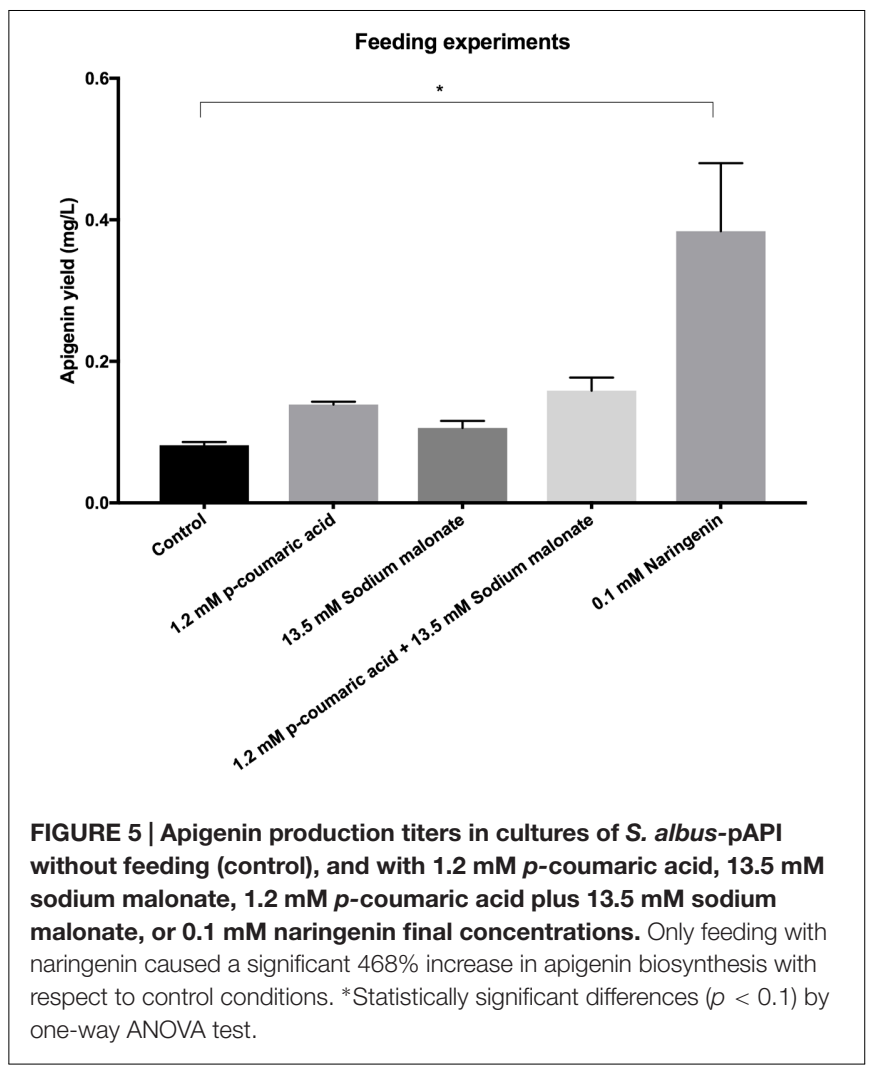

with p-coumaric acid (Lee et al., 2015). Higher production levels in $E$. coli, $110 \mathrm{mg} / \mathrm{L}$, have been described after feeding with p-coumaric acid and malonate (Leonard et al., 2008). This flavone was also produced in $S$. venezuelae at $1.5 \mathrm{mg} / \mathrm{L}$, but only after feeding with $0.5 \mathrm{mM}(136 \mathrm{mg} / \mathrm{L})$ naringenin a S. venezuelae strain which contained only the gene coding for FNS oxidoreductase (Park et al., 2010) (Table 3).

In this work, however, the complete biosynthetic pathway for apigenin was heterologous expressed in S. albus. Besides, it was not supplemented with any precursor, although the levels of apigenin obtained $(0.089 \mathrm{mg} / \mathrm{L})$ were smaller than in other previously described works. Only small amounts $(0.001 \mathrm{mg} / \mathrm{L})$ of its immediate precursor naringenin were detected, indicating that the activity of the plant oxidoreductase enzyme FNS is good in this microorganism.

In the case of eriodictyol, according to the literature, its biosynthesis in actinomycetes had not been described before. However, two research groups have reported production of this flavanone in E. coli from glucose or after feeding with p-coumaric acid plus malonate, caffeic acid or L-tyrosine, reaching production levels of $50,5.70,0.02$, and $42.6 \mathrm{mg} / \mathrm{L}$ respectively (Leonard et al., 2007, 2008; Zhu S. et al., 2014) (Table 3). In both cases, metabolic engineering in E. coli was carried out afterward to enhance the availability of the flavonoids precursor malonyl-CoA, increasing the eriodictyol production levels to 52 and $107 \mathrm{mg} / \mathrm{L}$ respectively (Leonard et al., 2007; Zhu S. et al., 2014) (Table 3). In our case, despite the low eriodictyol production levels in S. albus, this biosynthesis is de novo and 
TABLE 3 | List of heterologous microbial hosts for biosynthesis of flavanones and flavones in the literature and estimated production titers.

\begin{tabular}{|c|c|c|c|c|}
\hline Heterologous flavonoid produced & Host & Externally fed precursor & Production titers (mg/L) & Reference \\
\hline \multirow[t]{6}{*}{ Apigenin } & E. coli & L-Tyrosine & 13 & Miyahisa et al., 2006 \\
\hline & E. coli & $p$-Coumaric acid & 23 & Lee et al., 2015 \\
\hline & S. venezuelae & Naringenin & 1.5 & Park et al., 2010 \\
\hline & S. venezuelae & $p$-Coumaric acid & 15.3 & Park et al., 2011 \\
\hline & S. cerevisiae & p-Coumaric acid & 3.5 & Leonard et al., 2005 \\
\hline & E. coli & $p$-Coumaric acid and malonate & 110 & Leonard et al., 2008 \\
\hline \multirow[t]{5}{*}{ Eriodictyol } & E. coli & Caffeic acid & 0.03 & Leonard et al., 2006 \\
\hline & E. coli & L-Tyrosine & 107 & Zhu S. et al., 2014 \\
\hline & S. cerevisiae & Caffeic acid & 6.5 & Yan et al., 2005 \\
\hline & S. cerevisiae & Caffeic acid & 20 & Leonard et al., 2005 \\
\hline & E. coli & p-Coumaric acid and malonate & 50 & Leonard et al., 2008 \\
\hline \multirow[t]{2}{*}{ Luteolin } & S. cerevisiae & Caffeic acid & 2 & Leonard et al., 2005 \\
\hline & E. coli & $p$-Coumaric acid and malonate & 4 & Leonard et al., 2008 \\
\hline
\end{tabular}

has been achieved in an actinomycete for the first time. This low production levels, as well as the accumulation of its precursors naringenin and $p$-coumaric acid, show a low activity for the hydroxylase $\mathrm{F}^{\prime} \mathrm{H}$ (see below).

In the case of the flavone luteolin, its heterologous biosynthesis has been described in E. coli $(4 \mathrm{mg} / \mathrm{L})$ and $S$. cerevisiae $(2 \mathrm{mg} / \mathrm{L})$ after feeding with $p$-coumaric acid plus malonate, or caffeic acid respectively (Leonard et al., 2005, 2008) (Table 3). In our case, we demonstrate its de novo biosynthesis in Streptomyces. Nonetheless, as in the case of eriodictyol, luteolin yields were low. This was expected after the observed eriodictyol results, as luteolin biosynthesis requires also the activity of $\mathrm{F}^{\prime} \mathrm{H}$ hydroxylase (Figure 1).

These experiments showed that $\mathrm{F}^{\prime} \mathrm{H}$ enzyme in $S$. albus is not able to completely transform naringenin into eriodictyol nor apigenin into luteolin. In $S$. albus-pLUT, no eriodictyol was observed, indicating that the FNS enzyme is quite more efficient than $\mathrm{F}^{\prime} \mathrm{H}$, as apigenin is detected in higher amounts here than eriodictyol. This idea is supported also by the fact that eriodictyol levels in S. albus-pERI were almost 300 times lower than apigenin levels in $S$. albus-pAPI. Other authors have described also that $\mathrm{P} 450$ hydroxylases like $\mathrm{F}^{\prime}{ }^{\prime} \mathrm{H}$ from eukaryotic origin may present low solubility in prokaryotic hosts, as in this case $S$. albus, because a membrane anchorage domain may not be suitable in prokaryote systems (Park et al., 2011). The hydroxylase $\mathrm{F}^{\prime} \mathrm{H}$ is a cytochrome $\mathrm{P} 450$-dependent monooxygenase which requires its integration into the membrane of the endoplasmic reticulum of plant cells as well as the presence of a P450-reductase carrying electrons from a donor to a NADPH P450 hemecore complex. Functional expression of these plant membranebound enzymes in microorganisms is a challenge due to several factors, such as protein insolubility (prokaryotes do not have endoplasmic reticulum membranes to bound) and cofactor incorporation (Burbulis and Winkel-Shirley, 1999; Chang et al., 2007; Fowler and Koffas, 2009). It has been shown that microbial expression of this family of enzymes is enhanced by engineering P450 reductases, in a way that these reductases are fused to the corresponding P450-dependent monooxygenase, and the membrane binding domain of these ones is deleted to increase solubility in prokaryotic cytoplasm. Following this strategy, soluble and functional chimeras have been obtained (Leonard et al., 2006; Leonard and Koffas, 2007; Zhu S. et al., 2014). These reasons for the monooxygenases counterparts could explain the very low $\mathrm{F}^{\prime} \mathrm{H}$ activity shown in this study as shown with the low lutein and eriodictyol levels in S. albus. Therefore, these studies in $S$. albus will pave the way in order to conduct further enzyme engineering in this type of enzymes, to achieve higher production titers (Zhu S. et al., 2014) (Table 3).

Finally, we have seen accumulation of $p$-coumaric acid in our three producing strains, the second metabolite in the pathway (after TAL activity on L-Tyr), which is common to all flavonoid biosynthetic pathways. $p$-Coumaric acid is converted to coumaroyl-CoA by the action of 4CL enzyme, which requires malonyl CoA to synthetize the corresponding flavonoid (naringenin chalcone in our case, Figure 1). Malonyl-CoA is therefore a limiting factor in flavonoid production, as it is also precursor for fatty acids biosynthesis (Winkel-Shirley, 2001). In fact, different authors consider that this influx of malonyl-CoA is the biggest bottleneck in the flavonoids biosynthesis, since three molecules of malonyl-CoA are needed to generate a molecule of eriodityol, apigenin, or luteolin in our case. Basal levels of this metabolite inside cells are relatively low, as it is regularly consumed during fatty acids biosynthesis, so low intracellular malonyl-CoA availability may restrict the efficient production of flavonoids in both E. coli and Streptomyces strains (Santos et al., 2011; Rathnasingh et al., 2012). Accordingly, diverse described strategies to increase flavonoids yields focused on increasing the intracellular pool of malonyl-CoA by overexpressing the acetyl-CoA carboxylase enzyme complex (ACC) in the host strain (Hwang et al., 2003; Miyahisa et al., 2006; Park et al., 2011; Wang et al., 2011). ACC overexpression increased cell concentration malonyl-CoA in a $278 \%$ in relation to the $E$. coli wild strain (Zhu S. et al., 2014). In our case, with so high intracellular $p$-coumaric acid accumulation in comparison to final flavonoids, we can hypothesize that the reason may be also a low supply of malonyl-CoA, due to its consumption by fatty acids biosynthesis in $S$. albus. However, feeding with pure $13.5 \mathrm{mM}$ sodium malonate final concentration in flasks 
did not generated a significant increase in production levels. The cause of this may be that initially identified similar genes in $S$. albus chromosome to matB (membrane malonate carrier protein) and matC (malonyl-CoA synthetase) from $S$. coelicolor counterparts (sco2443, sco2445) (Park et al., 2011), actually do carry out other enzymatic functions in $S$. albus, and therefore this bacterium cannot incorporate extracellular sodium malonate toward flavonoids biosynthesis. As this step is the bottleneck in flavonoids biosynthesis, addition of $p$-coumaric acid nor both precursors ( $p$-coumaric acid plus sodium malonate) does not increase apigenin final titers (Figure 5). In order to check if feeding with the precursor naringenin was an alternative for increasing final apigenin levels, $0.1 \mathrm{mM}$ of this flavanone were added to $S$. albus-pAPI cultures, and in this case, apigenin production levels were increased $468 \%$ (Figure 5). Once we have achieved biosynthesis of these four flavonoids in S. albus, future metabolic engineering in this actinomycete, where the genome information is available, will be able to increase carbon flux toward malonyl-CoA, most probably leading to higher flavonoids production levels. Also, it will be possible to enhance intracellular production levels for $p$-coumaric acid, or limit at some degree possible catabolism pathways or enzymes affecting these precursors or flavonoid intermediates.

With respect to other heterologous hosts for production of bioactives as flavonoids, actinomycetes as $S$. albus, do possess the same degree of available genetic tools for genome and metabolic engineering, in comparison to E. coli, but more suitable and easier genetic tools than in the case of the eukaryote $S$. cerevisiae, which has the disadvantage that two copies for each gene function must be modify. As an extra advantage, the huge genetic and metabolic richness derived from large actinomycetes chromosomes allows these bacteria to possess a high diversity of anabolic and catabolic pathways in charge of providing different precursors needed for heterologous biosynthesis of a wide fan of bioactives, as it has been described in "Introduction" (Newman and Cragg, 2007).

With respect to the Gram-negative E. coli host, production of nutraceuticals like flavonoids for the pharmaceutical industries is favored in Gram-positives as S. albus. The reason for this is that $S$. albus, as a canonical Gram-positive bacterium, lacks the presence of important endotoxins for human cells, as those derived from $E$. coli outer membrane. Industrial removal of these

\section{REFERENCES}

Aguirrezabalaga, I., Olano, C., Allende, N., Rodriguez, L., Braña, A. F., Méndez, C., et al. (2000). Identification and expression of genes involved in biosynthesis of L-oleandrose and its intermediate L-olivose in the oleandomycin producer Streptomyces antibioticus. Antimicrob. Agents Chemother. 44, 1266-1275. doi: 10.1128/AAC.44.5.1266-1275.2000

Álvarez-Álvarez, R., Botas, A., Albillos, S. M., Rumbero, A., Martín, J. F., and Liras, P. (2015). Molecular genetics of naringenin biosynthesis, a typical plant secondary metabolite produced by Streptomyces clavuligerus. Microb. Cell Fact. 14:178. doi: 10.1186/s12934-015-0373-7

Bradford, M. M. (1976). A rapid and sensitive method for the quantitation of microgram quantities of protein utilizing the principle of protein-dye binding. Anal. Biochem. 72, 248-254. doi: 10.1016/0003-2697(76)90527-3 lipopolysaccharide toxins involves costly procedures (Lopes et al., 2010).

As an actinomycete, $S$. albus shows has a complex cell cycle that can be modified in order to further increase production yields of secondary metabolism heterologous bioactives. Secondary metabolism is activated during the MII stage (Manteca et al., 2008). In this work, we have carried out de novo production of apigenin in S. albus-pAPI strain by using three alternative cultivation approaches, with and without spore conditioning (Manteca et al., 2008). It is noticeable that similar production levels were obtained in conditioned and not conditioned cultures, but production was anticipated up to 2 days in the conditioned cultures, even with a delayed growth during the first 24-h. Consequently, conditioned cultures can be useful to manipulate production rates in eventual $S$. albus industrial fermentations, as it was reported in other streptomycetes (Sánchez and Braña, 1996; Rioseras et al., 2014).

\section{AUTHOR CONTRIBUTIONS}

LM and IG-d-R were involved in creation of the different recombinant plasmids and heterologous production strains. $\mathrm{CV}$ and FL were supervisors of these experiments. PY and AM contributed to the perform conditioning experiments. FL is principal investigator of the research project were these experiments were planned.

\section{FUNDING}

Authors wish to thank the Spanish Ministry of Economy and Competitiveness (MINECO, for financial support via Grant AGL2010-20622), and also to the Government of the Principality of Asturias (program PCTI for a Technology Transfer Grant).

\section{ACKNOWLEDGMENT}

Authors wish to thank Sergio Cueto, Ph.D., from Servicios Científico-Técnicos at the University of Oviedo, for his help with HPLC chromatography and purification of compounds.

Brosius, J. (1989). Superpolylinkers in cloning and expression vectors. DNA 8, 759-777. doi: 10.1089/dna.1989.8.759

Burbulis, I. E., and Winkel-Shirley, B. (1999). Interactions among enzymes of the Arabidopsis flavonoid biosynthetic pathway. Proc. Natl. Acad. Sci. U.S.A. 96, 12929-12934. doi: 10.1073/pnas.96.22.12929

Chang, M. C. Y., Eachus, R. A., Trieu, W., Ro, D.-K., and Keasling, J. D. (2007). Engineering Escherichia coli for production of functionalized terpenoids using plant P450s. Nat. Chem. Biol. 3, 274-277. doi: 10.1038/nchem bio875

Chater, K. F., and Wilde, L. C. (1980). Streptomyces albus G mutants defective in the SalGI restriction-modification system. J. Gen. Microbiol. 116, 323-334. doi: 10.1099/00221287-116-2-323

Chaudhuri, S., Sengupta, B., Taylor, J., Pahari, B. P., and Sengupta, P. K. (2013). Interactions of dietary flavonoids with proteins: insights from fluorescence 
spectroscopy and other related biophysical studies. Curr. Drug Metab. 14, 491-503. doi: 10.2174/1389200211314040011

Crozier, A., Jaganath, I. B., and Clifford, M. N. (2009). Dietary phenolics: chemistry, bioavailability and effects on health. Nat. Prod. Rep. 26, 1001-1043. doi: $10.1039 / \mathrm{b} 802662 \mathrm{a}$

Falcone Ferreyra, M. L., Rius, S. P., and Casati, P. (2012). Flavonoids: biosynthesis, biological functions, and biotechnological applications. Front. Plant Sci. 3:222. doi: $10.3389 /$ fpls.2012.00222

Fantini, M., Benvenuto, M., Masuelli, L., Frajese, G., Tresoldi, I., Modesti, A., et al. (2015). In vitro and in vivo antitumoral effects of combinations of polyphenols, or polyphenols and anticancer drugs: perspectives on cancer treatment. Int. J. Mol. Sci. 16, 9236-9282. doi: 10.3390/ijms16059236

Fernández, E., Weissbach, U., Reillo, S., Braña, F., Méndez, C., Rohr, J., et al. (1998). Identification of two genes from Streptomyces argillaceus encoding glycosyltransferases involved in transfer of a disaccharide during biosynthesis of the antitumor drug mithramycin. Yournal Bacteriol. 180, 4929-4937.

Fowler, Z. L., and Koffas, M. A. G. (2009). Biosynthesis and biotechnological production of flavanones: current state and perspectives. Appl. Microbiol. Biotechnol. 83, 799-808. doi: 10.1007/s00253-009-2039-z

González-Vallinas, M., González-Castejón, M., Rodríguez-Casado, A., and Ramírez de Molina, A. (2013). Dietary phytochemicals in cancer prevention and therapy: A complementary approach with promising perspectives. Nutr. Rev. 71, 585-599. doi: 10.1111/nure.12051

Hollman, P. C. H. (2014). Unravelling of the health effects of polyphenols is a complex puzzle complicated by metabolism. Arch. Biochem. Biophys. 559, 100-105. doi: 10.1016/j.abb.2014.04.013

Hwang, E. I., Kaneko, M., Ohnishi, Y., and Horinouchi, S. (2003). Production of plant-specific flavanones by Escherichia coli containing an artificial gene cluster. Appl. Environ. Microbiol. 69, 2699-2706. doi: 10.1128/AEM.69. 5.2699

Hwang, K.-S., Kim, H. U., Charusanti, P., Palsson, B. $\varnothing$, and Lee, S. Y. (2014). Systems biology and biotechnology of Streptomyces species for the production of secondary metabolites. Biotechnol. Adv. 32, 255-268. doi: 10.1016/j.biotechadv.2013.10.008

Kieser, T., Bibb, M. J., Buttner, M. J., Chater, K. F., and Hopwood, D. A. (2000). Practical Streptomyces Genetics. Norwich: John Innes Cent. Ltd, 529.

Kumar, S., and Pandey, A. K. (2007). Chemistry and biological activities of flavonoids: an overview. Sci. World J. 73, 637-670. doi: 10.1070/ RC2004v073n07ABEH000856

Lee, H., Kim, B. G., Kim, M., and Ahn, J.-H. (2015). Biosynthesis of two flavones, apigenin and genkwanin, in Escherichia coli. J. Microbiol. Biotechnol. 25, 1442-1448. doi: 10.4014/jmb.1503.03011

Leonard, E., and Koffas, M. A. G. (2007). Engineering of artificial plant cytochrome P450 enzymes for synthesis of isoflavones by Escherichia coli. Appl. Environ Microbiol. 73, 7246-7251. doi: 10.1128/AEM.01411-07

Leonard, E., Lim, K.-H., Saw, P.-N., and Koffas, M. A. G. (2007). Engineering central metabolic pathways for high-level flavonoid production in Escherichia coli. Appl. Environ. Microbiol. 73, 3877-3886. doi: 10.1128/AEM. 00200-07

Leonard, E., Yan, Y., Fowler, Z. L., Li, Z., Lim, C.-G., Lim, K.-H., et al. (2008). Strain improvement of recombinant Escherichia coli for efficient production of plant flavonoids. Mol. Pharm. 5, 257-265. doi: 10.1021/mp7001472

Leonard, E., Yan, Y., and Koffas, M. A. G. (2006). Functional expression of a P450 flavonoid hydroxylase for the biosynthesis of plant-specific hydroxylated flavonols in Escherichia coli. Metab. Eng. 8, 172-181. doi: 10.1016/j.ymben.2005. 11.001

Leonard, E., Yan, Y., Lim, K. H., and Koffas, M. A. G. (2005). Investigation of two distinct flavone synthases for plant-specific flavone biosynthesis in Saccharomyces cerevisiae. Appl. Environ. Microbiol. 71, 8241-8248. doi: 10.1128/ AEM.71.12.8241-8248.2005

Li, A., Li, S., Zhang, Y., Xu, X., Chen, Y., and Li, H. (2014). Resources and biological activities of natural polyphenols. Nutrients 6, 6020-6047. doi: $10.3390 /$ nu6126020

Liu, R. H. (2013). Health-promoting components of fruits and vegetables in the diet. Adv. Nutr, 4, 384S-392S. doi: 10.3945/an.112.003517.convenient

Lopes, A. M., Magalhães, P. O., Mazzola, P. G., Rangel-Yagui, C. O., De Carvalho, J. C. M., Penna, T. C. V., et al. (2010). LPS removal from an E. coli fermentation broth using aqueous two-phase micellar system. Biotechnol. Prog. 26, 1644-1653. doi: 10.1002/btpr.463

López-Lázaro, M. (2006). Hypoxia-inducible factor 1 as a possible target for cancer chemoprevention. Cancer Epidemiol. Biomarkers Prev. 15, 2332-2335. doi: 10.1158/1055-9965.EPI-06-0369

Luo, C., Yang, H., Tang, C., Yao, G., Kong, L., He, H., et al. (2015). Kaempferol alleviates insulin resistance via hepatic IKK/NF-кB signal in type 2 diabetic rats. Int. Immunopharmacol. 28, 744-750. doi: 10.1016/j.intimp.2015. 07.018

Manach, C., Scalbert, A., Morand, C., Rémésy, C., and Jiménez, L. (2004). Polyphenols: Food sources and bioavailability. Am. J. Clin. Nutr. 79, 727-747. doi: $10.1038 /$ nature 05488

Manteca, A., Alvarez, R., Salazar, N., Yagüe, P., and Sanchez, J. (2008). Mycelium differentiation and antibiotic production in submerged cultures of Streptomyces coelicolor. Appl. Environ. Microbiol. 74, 3877-3886. doi: 10.1128/ AEM.02715-07

Miyahisa, I., Funa, N., Ohnishi, Y., Martens, S., Moriguchi, T., and Horinouchi, S. (2006). Combinatorial biosynthesis of flavones and flavonols in Escherichia coli. Appl. Microbiol. Biotechnol. 71, 53-58. doi: 10.1007/s00253-0050116-5

Newman, D. J., and Cragg, G. M. (2007). Natural products as sources of new drugs over the last 25 years. J. Nat. Prod. 70, 461-477. doi: 10.1021/np068054v

Park, S. R., Ahn, M. S., Han, A. R., Park, J. W., and Yoon, Y. J. (2011) Enhanced flavonoid production in Streptomyces venezuelae via metabolic engineering. J. Microbiol. Biotechnol. 21, 1143-1146. doi: 10.4014/jmb.1108. 08012

Park, S. R., Paik, J. H., Ahn, M. S., Park, J. W., and Yoon, Y. J. (2010). Biosynthesis of plant-specific flavones and flavonols in streptomyces venezuelae. J. Microbiol. Biotechnol. 20, 1295-1299. doi: 10.4014/jmb.1005.05038

Park, S. R., Yoon, J. A., Paik, J. H., Park, J. W., Jung, W. S., Ban, Y.-H., et al. (2009). Engineering of plant-specific phenylpropanoids biosynthesis in Streptomyces venezuelae. J. Biotechnol. 141, 181-188. doi: 10.1016/j.jbiotec.2009. 03.013

Rathnasingh, C., Raj, S. M., Lee, Y., Catherine, C., Ashok, S., and Park, S. (2012). Production of 3-hydroxypropionic acid via malonyl-CoA pathway using recombinant Escherichia coli strains. J. Biotechnol. 157, 633-640. doi: 10.1016/j. jbiotec.2011.06.008

Ravishankar, D., Rajora, A. K., Greco, F., and Osborn, H. M. I. (2013). Flavonoids as prospective compounds for anti-cancer therapy. Int. J. Biochem. Cell Biol. 45 , 2821-2831. doi: 10.1016/j.biocel.2013.10.004

Rioseras, B., López-García, M. T., Yagüe, P., Sánchez, J., and Manteca, A. (2014). Mycelium differentiation and development of Streptomyces coelicolor in labscale bioreactors: programmed cell death, differentiation, and lysis are closely linked to undecylprodigiosin and actinorhodin production. Bioresour. Technol. 151, 191-198. doi: 10.1016/j.biortech.2013.10.068

Sánchez, L., and Braña, A. F. (1996). Cell density influences antibiotic biosynthesis in Streptomyces clavuligerus. Microbiology 142( Pt 5), 1209-1220. doi: 10.1099/ 13500872-142-5-1209

Santos, C. N. S., Koffas, M., and Stephanopoulos, G. (2011). Optimization of a heterologous pathway for the production of flavonoids from glucose. Metab. Eng. 13, 392-400. doi: 10.1016/j.ymben.2011.02.002

Tong, X., and Pelling, J. C. (2013). Targeting the PI3K/Akt/mTOR axis by apigenin for cancer prevention. Anticancer. Agents Med. Chem. 13, 971-978. doi: 10.2174/18715206113139990119

Trantas, E., Panopoulos, N., and Ververidis, F. (2009). Metabolic engineering of the complete pathway leading to heterologous biosynthesis of various flavonoids and stilbenoids in Saccharomyces cerevisiae. Metab. Eng. 11, 355-366. doi: 10.1016/j.ymben.2009.07.004

Trantas, E. A., Koffas, M. A. G., Xu, P., and Ververidis, F. (2015). When plants produce not enough or at all: metabolic engineering of flavonoids in microbial hosts. Front. Plant Sci. 6:7. doi: 10.3389/fpls.2015.00007

Tsao, R. (2010). Chemistry and biochemistry of dietary polyphenols. Nutrients 2 , 1231-1246. doi: 10.3390/nu2121231

Verma, A. K., and Pratap, R. (2010). The biological potential of flavones. Nat. Prod. Rep. 27, 1571-1593. doi: 10.1039/c004698c

Wang, Y., Chen, S., and Yu, O. (2011). Metabolic engineering of flavonoids in plants and microorganisms. Appl. Microbiol. Biotechnol. 91, 949-956. doi: 10.1007/s00253-011-3449-2 
Winkel-Shirley, B. (2001). Flavonoid biosynthesis. A colorful model for genetics, biochemistry, cell biology, and biotechnology. Plant Physiol. 126, 485-493. doi: $10.1104 /$ pp.126.2.485

Wu, J., Du, G., Zhou, J., and Chen, J. (2014). Systems metabolic engineering of microorganisms to achieve large-scale production of flavonoid scaffolds. J. Biotechnol. 188, 72-80. doi: 10.1016/j.jbiotec.2014.08.016

Yan, Y., Kohli, A., and Koffas, M. A. G. (2005). Biosynthesis of natural flavanones in Saccharomyces cerevisiae. Appl. Environ. Microbiol. 71, 5610-5613. doi: 10.1128/AEM.71.9.5610-5613.2005

Zhang, H., Wang, Y., and Pfeifer, B. A. (2008). Bacterial hosts for natural product production. Mol. Pharm. 5, 212-225. doi: 10.1021/mp7001329

Zhu, L., Olsen, C., McHugh, T., Friedman, M., Jaroni, D., and Ravishankar, S. (2014). Apple, carrot, and hibiscus edible films containing the plant antimicrobials carvacrol and cinnamaldehyde inactivate Salmonella newport on organic leafy greens in sealed plastic bags. J. Food Sci. 79, M61-M66. doi: $10.1111 / 1750-3841.12318$
Zhu, S., Wu, J., Du, G., Zhou, J., and Chen, J. (2014). Efficient synthesis of eriodictyol from L-tyrosine in Escherichia coli. Appl. Environ. Microbiol. 80, 3072-3080. doi: 10.1128/AEM. 03986-13

Conflict of Interest Statement: The authors declare that the research was conducted in the absence of any commercial or financial relationships that could be construed as a potential conflict of interest.

Copyright (C) 2017 Marín, Gutiérrez-del-Río, Yagüe, Manteca, Villar and Lombó. This is an open-access article distributed under the terms of the Creative Commons Attribution License (CC BY). The use, distribution or reproduction in other forums is permitted, provided the original author(s) or licensor are credited and that the original publication in this journal is cited, in accordance with accepted academic practice. No use, distribution or reproduction is permitted which does not comply with these terms. 